\title{
Botanical ingredient identification and quality assessment: strengths and limitations of analytical techniques
}

\author{
Roy Upton · Bruno David $\cdot$ Stefan Gafner $\cdot$ Sabine Glasl $\mathbb{C}$
}

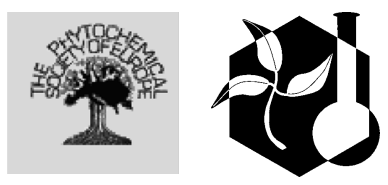

Received: 1 March 2019/Accepted: 28 June 2019/Published online: 9 July 2019

(C) The Author(s) 2019

\begin{abstract}
Interest in botanical medicines is increasing worldwide with current global market values estimated to be greater than US $\$ 72$ billion. To ensure ingredients used in botanical preparations are appropriately identified and will deliver the intended benefit while minimizing potential for risk, good manufacturing practices (GMPs) are required. GMPs require that scientifically valid analytical techniques be used. This review discusses a variety of techniques of quality assessment taking into account the different challenges between academicians and manufacturers with the basic premise that all techniques are scientifically valid if used appropriately, and conversely, are limited if not used in a scientifically valid manner. The strengths and limitations, applications and
\end{abstract}

R. Upton

American Herbal Pharmacopoeia,

PO Box 66809, Scotts Valley, CA, USA

B. David

Green Mission Pierre Fabre, Institut de Recherche Pierre Fabre Toulouse, 3, Avenue Hubert Curien, BP 13562,

31562 Toulouse, France

S. Gafner

American Botanical Council, PO Box 144345, Austin, TX 78714, USA

S. Glasl $(\bowtie)$

Department of Pharmacognosy, University of Vienna, Althanstraße 14, 1090 Vienna, Austria

e-mail: sabine.glasl@univie.ac.at inapplicability, of some of these techniques will be discussed, as will differences between traditional and more modern analytical techniques. A strong emphasis is placed on classical botanical and traditional macromorphological assessment techniques that represent the basis of identification and quality assessment upstream of other techniques such as analytical chemistry and genetics. It will be shown that it is the suite of botanical and chemical techniques that provides the greatest confidence for ensuring the identity and quality of botanical medicines.

Keywords Botanical identification - Quality assessment · Botanical medicines · Botany · Quality control
Abbreviations
BRM Botanical reference material
CRM Chemical reference material
CRS Chemical reference standard
TCM Traditional Chinese medicine
WHO World Health Organization

\section{Introduction}

Botanical medicines are gaining in importance worldwide, which is reflected both by the health benefits consumers believe they receive (Chandiraleka and 
Hamsalakshmi 2016; Oldendick et al. 2000) and a rapidly growing global market that was estimated at US $\$ 72$ billion in 2016 (Hexa Research 2017) and projects to increase to more than US $\$ 111$ billion by 2023 (Reuters 2018). Much of this growth is driven by increasing interest in traditional systems of herbal medicine including Ayurveda and traditional Chinese medicine. This growth is paralleled by a continuously growing scientific interest for herbal medicine research, which is evidenced by exponential increases in the number of publications in recent decades (Wegener 2017). Central to the manufacture of botanical medicines is the application of appropriate analytical techniques to ensure their quality, purity, and safety through adherence to good manufacturing practices (GMPs). In most cases, GMPs are mandated according to national regulatory models that vary depending on whether botanical preparations are defined as "traditional medicines" (European Union, Asia, and India), "natural health products" (Canada), or either "dietary supplements" or "botanical drugs" in the United States. In all cases in which regulatory models exist, a variety of analytical techniques are available, each with inherent strengths and limitations.

Throughout history to current times, botany has been the primary technique used for the identification of plants of economic and medicinal importance. In traditional healing systems, such as with Ayurveda and traditional Chinese medicine (TCM), macromorphological and sensory (organoleptic) assessment techniques are applied to ensure the identity, purity, quality, and activity of medicinal plants. The advent of analytical chemistry in the 1800 s and refinement of plant-based drugs to isolated or synthetic constituents reflected in modern medicines caused these traditional techniques to be overshadowed with the premise that only chemistry was needed to ensure the quality and efficacy of medicines. Today, molecular assessment of plants is challenging classical botany as the fundamental basis of plant identification. In actuality, all analytical techniques are critical to the evaluation of medicinal plant ingredients and no single technique is superior to another. The scientific validity of a technique depends on the analytical goal and is reflected in the concept of "fit-for-purpose" "in which quality is determined as the extent to which a programme of assessment fulfills its purpose or its function" (Dijkstra et al. 2012).
There is a real challenge in ensuring the authenticity of medicinal plant parts as the majority of botanical ingredients in trade are composites of multiple batches from multiple sources making documentation of identity of a particular batch difficult. Moreover, the international supply chain often lacks the botanical expertise to provide adequate documentation of the identification of plant materials whether wild-harvested or cultivated. Analysts often do not know what analytical techniques are appropriate for what analytical endpoint in the varying matrices that occur (live plant, crude plant part, extract). Researchers often do not understand the steps needed to ensure the integrity of the botanical identity and quality of test materials when conducting research and need guidance. This review places strong emphasis on botany as a basic discipline in pharmacognostic research and reflects on botanical nomenclature including its historical development and imprecise use in popular and scientific literature. The different needs of academicians and manufacturers in regards to plant identification are outlined, and strengths and limitations of established techniques for valid identification are discussed.

\section{Plant nomenclature}

\section{Scientific nomenclature}

Assuring quality control of medicinal plants begins with the identification of the purported plant. In botany, unequivocal nomenclature plays a key role for the precise definition of the vegetal material used in botanical medicines and food supplements, or plants studied by phytochemists (Applequist 2015). The evidence base of herbal medicines, whether investigating chemistry, pharmacology, or toxicology, requires accurate and universally accepted names of the contained botanicals. These names should be constant and unique. However, botanical names assigned to species do not necessarily cover species in the naturalistic sense. Historically, and in traditional cultures different vernacular names may describe the same species, and vice versa, for different species the same common name may be used.

While medicinal plants are known to the general public by their common names, Latin, due to its specificity, is the official language of botanists (and science in general). In former times, for the sake of 
precision, species were described by authors in short descriptive sentences, so called polynomials. They were reworked from book to book and formeddepending on the author-a variable number of words that were rather long and non-homogenous. In a spirit of systematization, the French botanist Joseph Pitton de Tournefort (1656-1708) attributed each plant species to a genus, a synthetic unit formed by the union of neighbouring species (Tournefort 1694). Botanical nomenclature was further extended by the Swedish botanist Carl von Linné (also known as Carolus Linnaeus; 1710-1778) by removing the cumbersome and fluctuating polynomials (Linnaeus 1753). Linnaeus introduced the Latin binominal botanical nomenclature designating each plant species by two words: The generic (genus) name written with the first letter capitalized (e.g. Achillea) and an epithet (designating the species within the genus) written in lower case (e.g. millefolium). Both the genus and species names are italicized. To avoid confusion, an epithet consists of only one gender name. For purposes of botanical preciseness, the Latin binomial of a plant is completed by inclusion of the name of the author whose description of the species has been formally accepted (e.g. Linnaeus). In botanical nomenclature, authors' names are standardized and typically abbreviated (e.g. Achillea millefolium L.). This allows for any future investigation to go back to the original description and usually is important in case of taxonomic reclassification.

The publication of a new species requires the citation of a reference botanical sample called the "nomenclatural type" or "type specimen" of the species. Since a species in nature exists as populations of individuals that may not all be identical, it is the task of the first describer to understand what a species is, to comprehend this variation and study as many specimens as possible in order to select the most appropriate individual for the "nomenclatural type". This herbarium sample has to be preserved in a large official collection as a voucher, designated as "type specimen", which bears an indissolubly attached label containing information about date and site of collection, collector, determinator etc. The starting point fixed for the binominal nomenclature is the date of publication of the first edition of Linnaeus' Species Plantarum attributed to May 1, 1753 (Linnaeus 1753). The names prior to this date are said to be pre-Linnean and considered as non-existent. During the nineteenth century, botanists improved the understanding of the hierarchy needed in systematic botany. This knowledge and need of formalisation led to the first botanical code adopted by the Botanical Congress held in Vienna in 1905. This Botanical Code (known as the "International Code of Nomenclature for algae, fungi, and plants") has been reviewed since that time every six years. The current version is the Shenzhen Code adopted in July 2017 by the International Botanical Congress in Shenzhen (Turland et al. 2018). As the Botanical Code was not appropriate for non-Latin commercial and ornamental hybrids, cultigens' names, grexes and ranks below the species level, a Code of Nomenclature for Cultivated Plants known as the 'Cultivated Plant Code' was established and adopted in 1952 in Wageningen. The current version of this Code is the 2016 issue (Brickell et al. 2016).

An important point regarding nomenclature is the synonyms' issue. More than 1.06 million of plant binomials are reported in The Plant List (www. theplantlist.org) for about only 370,000 plant species (Paton et al. 2016). Therefore, many plants have multiple binomials instead of one unique and unequivocal binomial (Dauncey et al. 2016). As an example Catharanthus roseus (L.) G. Don the accepted name of the tropical periwinkle has several synonyms: Pervinca rosea (L.) Gaterau, Vinca speciosa Salisb., Lochnera rosea (L.) Rchb. ex Spach and Ammocallis rosea (L.) Small.

In order to check the accepted names and synonyms the most useful and reliable botanical websites are: Medicinal Plant Names Services (www.kew.org/ MPNS), The International Plant Names Index (www. ipni.org), The Plant List, Tropicos (www.tropicos. org), the World Checklist of Selected Plant Families (https://wcsp.science.kew.org/qsearch.do) and The Germplasm Resources Information Network (GRIN) (www.ars-grin.gov).

Botanical nomenclature is not always straightforward as the various botanical authorities (e.g. Royal Botanical Garden-Kew, Missouri Botanical Garden [MOBOT]) often are contradictory. However, the botanical congresses are dedicated to developing consensus and define a unique valid binomial for every species. The controversies between botanists are a part of the permanently ongoing taxonomic process and nomenclatural classifications continue to evolve. Utilization of genetic techniques (DNA) often challenge classical taxonomic findings and can lead to new 
taxonomic investigations and designations. A phylogenetic classification system was developed by the Angiosperms Phylogeny Group in 1998 (APG I) and replaced by APG II (2003) and APG III (2009). The latest phylogenetic classification (2016) is APG IV (Byng et al. 2016). For this reason, it is common to see that a plant currently placed in a botanical family, will later be classified in another family responding to a new classification. This might be the reason whydespite these codes and very strict rules regarding botanical nomenclature-more than $30 \%$ of the scientific plant names cited in phytochemical journals are erroneous (Rivera et al. 2014), suggesting that preciseness in botanical nomenclature is a desired goal not yet fully realized. Therefore, it is absolutely essential that botanical vouchers are deposited, catalogued, and preserved in a herbarium of a scientific institution as the cornerstone of botanical information and basis of any scientific paper on a plant. Approximately 350 million specimens preserved in some 3000 herbaria throughout the world furnish the material for the work of botanists in their endeavour to inventory, accurately name, and describe vegetal biodiversity. However, information provided by vouchers must be questioned as, according to Goodwin et al. (2015), incorrect identifications have occurred for up to $60 \%$ of examined tropical taxa. The trend of many respective institutions to digitalize a large number of their botanical collections in order to make them available on the web has to be assessed as extremely positive and will hopefully remain ongoing in the future.

\section{Nomenclature in practise}

In commerce, vernacular (common) names are most familiar to stakeholders, traders and consumers (e.g. common "tea" vs. the Latin "Camellia sinensis") and are most relevant in the labelling of finished products. However, there is no internationally recognized source that correlates common names with a specific Latin binomial or binomials in the case when multiple species are accepted. This is partially addressed by Herbs of Commerce, an English-language text that attempts to correlate specific common names with specific Latin binomials and is recognized in the Code of Federal Regulations of the United States (CFR 2007). The Medicinal Plant Names Service is another resource that provides a record of common names,
Latin binomials, and synonyms used in the naming of medicinal plants.

In the current global exchange of botanical ingredients across borders and cultures, it must also be recognized that non-Western names are more familiar to certain groups, e.g. traditional Chinese or Ayurvedic practitioners or consumers of these traditional medicines, but may be unfamiliar to Westerners. Therefore, in the global trade of botanical ingredients, especially for medicines or health products, it would be highly desirable, if academicians, scientific investigators, herb traders, and manufacturers consequently used Latin binomials including the author names, as these are unequivocal, scientific, and cross-culturally accepted, regardless of language and alphabetical system. From a scientific perspective, the author names are an integral part of botanical nomenclature providing the scientific basis of the original naming. However, in practise scientifically correct nomenclature is often neglected resulting in misspellings, missing authors to a binomial, and homonyms, which altogether represent a source of confusion (Dauncey et al. 2016). The author name is not merely decorative since it is crucial for homonyms differentiation. For example, Pinus abies L. is a synonym of Picea abies (L.) H. Karst (Pinaceae) while Pinus abies Lour. is a synonym of Cunninghamia lanceolata (Lamb.) Hook. (Taxodiaceae) (Rivera et al. 2014). The two homonymic species belong to two distinct families which are in no way related.

The consequences of a lack of care regarding nomenclature result in errors about the material, information published under different names, pseudo novelty in research publication, failure to retrieve relevant data, etc. When synonyms are more familiar than the accepted binomial the binomial should be used and the synonym placed in brackets e.g. Matricaria chamomilla L. (syn. Matricaria recutita L.) (Dauncey et al. 2016).

Use of complete scientific binomial nomenclature is most critical to ensure the scientific integrity of the published literature (Bennett and Balick 2014). As an example, in popular markets, the common name ginseng designates at least a dozen different species from six different genera. If there is no traceability to a particular species, use of the name ginseng alone provides no basis of evidence which species was investigated. Use of pharmaceutical names, e.g. Ginseng radix, provides a greater degree of accuracy than 
common names in that pharmacopoeial monographs limit the number of species that are acceptable and provide a suite of identification, purity, and quality tests that are meant to ensure the article of trade conforms to the proscribed identity and quality standards. Use of unvalid synonyms instead of the unique valid scientific name or valid synonyms is responsible for unintentional errors in the literature generating pseudo novel or wrong phytochemical descriptions. The traceability of medicinal plant source material to a botanical voucher deposited in a recognized institution and identified by an expert of the taxon has been proposed as compulsory documentation for botanical investigations submitted to phytochemical journals (Zidorn 2017).

The same traceability represents best practices for all aspects of herbal medicine quality control and is something that industry should strive for. However, many botanicals in international trade are wildharvested or cultivated by people who lack taxonomic and botanical expertise. More challenging is that the majority of either cultivated or wild-harvested medicinal plants traded represent a wide variety of populations, often from diverse regions. It is impossible to develop botanical documentation for every one of the ten thousand plants that make up a single 1000 kilo batch of any botanical. For most materials it is unrealistic to expect herb traders to maintain a herbarium collection of every batch from every collector that provides raw material. Such a requirement could result in the formal identification, documentation, processing, storage, and maintenance of hundreds or thousands of vouchers per year for a single company. Additionally, the procurement of a botanical voucher alone does not guarantee the plant material is appropriate for medicinal use. For example, many plants are identified by their floral parts, which most often are blooming in spring or summer, but may not be the optimal time of harvest. Other plants (e.g. Panax ginseng, Angelica sinensis) must be a certain age before they are considered to be appropriate for medicinal use. Other medicinal plants (e.g. many anthraquinone-containing plants such as Rheum or Frangula species) may be processed or aged prior to use. A botanical voucher alone only provides documentation of identity not quality. Most medicinal plants in commercial trade lack the botanical characteristics needed to accurately identify the species with the same level of specificity as is possible with a live specimen or botanical pressing. The majority of traded medicinal plant material is traded dry, often comminuted to various degrees (chopped, cut, powdered, processed). The features of such material often do not match those given for fresh material in standard floras and botanical keys often lack identification information for barks and underground parts. Because of this, detailed characters for medicinal plant parts in trade and identity and quality tests are provided in pharmacopoeias.

\section{Macroscopic and organoleptic techniques}

Historical evolution

Early materia medicas lacked sufficient information for appropriately identifying medicinal plants. The earliest formal materia medica in the West, De Materia Medica of Pedanious Dioscorides (first century), lacked illustrations, and when descriptions were given, they were very sparse. The first medicinal plant descriptions inserted into this text occurred in the Codex Vindobonensis (Codex Vienna) in the sixth century, a stylized and illustrated version of $D e$ Materia Medica. While some of the illustrations were relatively representative of the plant, few could be used to distinguish two closely related species, and some were so abstract as to be completely unidentifiable. This was partially rectified by Leonhart Fuchs (1501-1566), one of four fathers of German botany, in his De Historia Stirpium Commentarii Insignes of 1542 who presented botanically accurate illustrations in his works. Prior to this, both physical descriptions and illustrations, when available, were relatively crude and lacked botanical specificity.

Throughout much of Western history botanical sciences were predominantly the provenance of medical practitioners who needed to identify medicinal plants. This lasted for approximately 1000 years, evolving from crude to highly exacting botanical illustrations, to crude and high-quality photographs in later and current works of pharmacognosy e.g. (DAC 2016; Leon and Lin 2017; Mansfield 1919; Wichtl 2004; Zhao and Chen 2014). The relationship between botany and medicine was so pronounced that early Greek physicians were known as rhizotomi (Morton 1981) and in later centuries as "medical botanists". Today, the relationship between these two disciplines 
no longer exists. This requires an approach to nomenclature that bridges the gap between the exacting specificity of botany versus the practices employed in traditional healing systems and pharmacopoeias to identify accptable materials.

In addition to the pure botanical descriptions that occurred in early medical botany works, many later medical botany texts such as the Renaissance herbals e.g. Theatrum Botanicum (Parkinson 1640) and some books of domestic medicine e.g. The New Family Herbal or Domestic Physician (Meyrick 1790) included descriptions of the medicinally relevant plant parts. These were later codified into pharmacopoeial descriptions. The Dispensatorium Lippiacum was the first formal western dispensatory to introduce organoleptic characterizations and the use of magnifiers as part of the assessment criteria for medicinal plant ingredients (Scherf 1792). Conversely, both macroscopic and organoleptic features, especially regarding qualitative distinctions, including preferred areas of harvest, were included in the earliest of Chinese and Indian herbal medicine literature (e.g. Shennong Bencao of China and Carak Samhita of India). The pharmacological basis of both Ayurvedic and Chinese herbal medicine begins with understanding the flavor and nature of medicinal agents. The flavor and nature of botanicals reflect the medicinal properties and chemical constituents of the plant. These are then directly correlated with diagnostic constructs that unite pharmacy and medicine, making the inclusion of these characters integral to understanding traditional medicine systems, systems that are uniquely different from Western approaches.

By the middle $1800 \mathrm{~s}$, macromorphological/ organoleptic descriptions were a standard feature in the majority of European and American dispensatories, materia medicas, and pharmacopoeias, including texts completely devoted to the general subject of pharmaceutical botany with exacting colored botanical illustrations, many of which included the plant part along with the plant (e.g. Berg and Schmidt 1863; Graves 1834). All modern pharmacopoeia monographs today include a morphological description of the plant drug under various descriptive headings such as: "Identification" in the European Pharmacopoeia; "Botanic Characteristics" in the United States Pharmacopeia (USP); and "Description" in the Ayurvedic Pharmacopoeia of India and Pharmacopoeia of the People's Republic of China. These sections primarily give the relative form, size, shape, and physical features of the crude plant drug. Additionally, pharmacopoeias and pharmacognosy literature provided detailed instruction of how an appropriate macroscopic and organoleptic assessment was to be performed on various plant parts. Today there is a plethora of references (e.g. API 2001; Applequist 2006; Leon and Lin 2017; Wichtl 2004; Zhao and Chen 2014) on the morphological assessment of crude plant drugs. These provide scientifically valid resources for identifying a large number of medicinal plants based on macromorphological and organoleptic characters to determine conformity with pharmacopoeial identification specifications and foster compliance with good manufacturing practices (GMPs).

Organoleptic assessment of medicinal plants

Macroscopic identification and sensory examination (alternatively referred to as organoleptics) techniques are primarily applied to crude plant materials. Materia medicas, pharmacognosy texts of the not-too-distant past, and pharmacopoeias provide detailed guidance, e.g. by descriptions of (1) Form; (2) Shape and size; (3) Color, external markings and texture; (4) Fracture and internal color; (5) Organoleptic characters (odor, taste, and mouthfeel). The presence of the expected characteristics represents key indications as to the plant's identity, while the intenseness, whether of color, aroma, or flavor provides direct indications of the plant's quality. The macroscopic assessment of crude plant materials allows for the immediate detection of foreign matter, filth, and potentially adulterating materials. It provides valuable insights for determining if the quality of the material is acceptable for use in medicinal products.

The visual characters are examined either by the naked eye or with a magnifier $(10 \times)$ : Specifically for the examination of leaves, the following characters were considered most relevant: Size, shape, margin, apex, base, and venation, and distribution of hairs and the presence, absence, and type of glands. In some cases, leaf material requires rehydration prior to examination as many leaves, especially those that are thin and papery, curl when dry. Rehydration allows for the leaf to be flattened and observed in its relatively intact form. The observable features are compared against a botanical reference material or against an authoritative description to determine if all observable 
features conform and that the sample lacks nonconforming features (Cooper et al. 1931). The leaves of Arctostaphylos uva-ursi, for example, are found in commerce in dried, whole, broken, cut and sifted, or powdered forms. Supplies generally consist of leaves with petioles either attached or broken off with occasional pieces of stems in the mixture. Uva ursi is prone to have browned or deteriorated leaves that lack the active constituent arbutin, and limits have been established in European Pharmacopoeia for restricting the inclusion of such leaves in herbal preparations (Upton et al. 2008). All of these features are observable in either whole or crudely cut leaves and the presence of conforming features and absence of non-conforming features can be documented as exemplified in Table 1 and Fig. 1.

Organoleptically, all sensory characters are considered relevant and include: Color, texture, odor, taste, and mouthfeel (Cooper et al. 1931; Mansfield 1926). When examining color or taste, it is both the color itself and intensity that is assessed. Berberine is a brilliant yellow or golden color and is very bitter. The presence and intensity of both color and flavor of herbs that contain berberine are direct indicators of the medicinal quality of a sample. As berberine-containing herbs, such as goldenseal root, age, the yellow coloring fades and is replaced by greenish hues and the bitter flavor diminishes. This is an indication the material was improperly dried or stored, or that the sample is old and deteriorated (Upton et al. 2001) and can be more objectively determined using the 'bitterness index', which is a testing criteria included in most pharmacopoeias.

The level of confidence in accurately assessing a material with a high degree of specificity varies between species, the forms in which the sample occurs (relatively whole of highly comminuted), and the skill level of the assessor. As with any analytical technique, analysts must have the requisite training for carrying out and documenting an assessment in a scientifically valid manner. To minimize the subjective nature of sensory assessment, formal organoleptic training was introduced to the conventional food, wine, and tea industries. A variety of flavor scales are employed for the primary flavors: Pungency (Scoville scale), sweetness, sour, salty, and fixed interval scales, along with the bitterness index previously mentioned, and training panels and procedures are established for "calibrating" organoleptic assessors. In addition to formal training in organoleptics, a number of electronic sensors have been developed, primarily for use in the wine industry. While not widely used in the herbal ingredients trade, some researchers have investigated their applicability in the botanical sectors (e.g. Jayasundar and Ghatak 2016), including the interface of these sensors with spectroscopic technologies, helping to more objectively establish correlations between flavors and chemistry (Miao et al. 2017). The value of classic macromorphological assessment of herbal drugs is underscored by WHO in their Guidelines for the Quality Assessment of Herbal Medicines that states:

Visual inspection provides the simplest and quickest means by which to establish identity, purity and, possibly, quality. If a sample is found to be significantly different, in terms of color, consistency, odor or taste, from the specifications, it is considered as not fulfilling in the requirements." (WHO 1998).

\section{Light microscopy}

The use of the first compound microscopes with incident light dates back to the seventeenth century. There is unclarity about when and by whom the first suitable instrument was invented, but among others Robert Hooke (1635-1703) was one of the first to describe various cells and units of cells providing the earliest observations of plant anatomy and physiology at the microscopic level (Hooke 1665). Later, the German botanist and professor of natural sciences Mathias Jacob Schleiden (1804-1881) introduced botanical microscopy as a key technique for distinguishing between the structural characteristics of different medicinal plants, originally showing that various species of sarsaparilla (Smilax) could be distinguished from each other due to the characteristic pattern of cellular structures that each possessed (Kraemer 1920).

As originally described by Schleiden, every plant has characteristic structures and structural tissue arrangements, some of which are unique. An analysis of the tissues and arrangement of structures can provide key information of the investigated material such as which organ is present, of what botanical family it may be a member, and, the identity of the species. Botanical microscopy, in particular, is uniquely valuable for the evaluation of dried plant 
Table 1 Macroscopic characteristics of Arctostaphylos uva-ursi leaves
Courtesy of: American Herbal Pharmacopoeia, Scotts Valley, CA

\begin{tabular}{ll}
\hline Botanical & Arctostaphylos uva-ursi leaves \\
\hline Form & Mixture of entire and/or broken leaves \\
Length & Up to $30 \mathrm{~mm}$ \\
Width & Up to $15 \mathrm{~mm}$ \\
Blade shape & Spatulate to oblong-spatulate to obovate \\
Petiole & Present; thick; up to $6 \mathrm{~mm}$ long \\
Apex & Rounded, obtuse, or acute \\
Margin & Entire, revolute \\
Base & Cuneate \\
Venation & Distinct, finely reticulate; slightly impressed \\
Texture & Coriaceous \\
Surface & Upper and lower smooth and shiny; young leaves pubescent \\
Color & Yellowish-green, to grayish green with shine \\
Fracture & N/a \\
Aroma & Slight, non-distinct \\
Taste & Astringent, slightly bitter \\
Unique feature & Reticulate venation \\
& Should have no more than 5\% foreign matter or 3\% deteriorated leaves \\
\hline &
\end{tabular}

materials whose characteristics are often dramatically altered from the fresh state. Drying and fragmentation of plants generally do not result in the loss of diagnostic microscopic features. Cut, sifted or even finely ground samples may be identified in cases in which the samples reveal peculiar characteristics like special type of trichomes, crystals, stomata, incrustations like cystoliths etc.

Botanical microscopy is also especially valuable in detecting admixtures of a different plant or different parts of the same plant. For example, the chemical profile of goldenseal (Hydrastis canadensis) root and leaf is very similar, so contamination of the desired root material with leaf can easily escape detection with standard chemical tests (e.g., HPTLC/HPLC) and if only looking at DNA. Conversely, it is very easy to identify the presence of leaf material contamination microscopically because the structural differences between root and leaf tissues are readily discernable. The same is true for the adulteration of the Chinese herbs Akebia, Clematis, and Stephania with Aristolochia species containing the highly nephrotoxic and carcinogenic compound aristolochic acid (AA). The latter may reliably be detected by the appearance of crystals which the other plants are missing (Upton et al. 2011). In this case microscopy is as reliable but much more quick and less expensive than chemical and genetic tests.

\section{Strengths and limitations of organoleptics, macroscopy and microscopy}

Organoleptic evaluation is relevant to all herbal materials that do not present either a risk of toxicity, if assessing the more potent herbal medicines (e.g. aconite [Aconitum spp.]), or potential allergens (e.g. Asteraceae) in those with particular sensitivities. For identification purposes, organoleptic characteristics can provide some indication that the material is what it is expected to be. The aroma of various mints such as peppermint (Mentha piperita), spearmint (Mentha spicata), pennyroyal (Mentha pulegium), and lemon mint (Mentha citrata) are very characteristic and distinctly different from each other-microscopically they are very similar. The heating quality of cayenne pepper (Capsicum spp.) and mucilaginous nature of slippery elm (Ulmus rubra) are equally indicative of identity, even when evaluating powders and extracts and are directly correlated with the plant's chemistry and medical activity. However, while the sensory characteristics of a particular sample are adequate to check its identity, it is difficult and sometimes impossible to determine through sensory perception if adulterating materials are present in processed materials (powders and extract).

Macroscopic evaluation of a plant material is relevant to all plant parts that are intact to a degree 


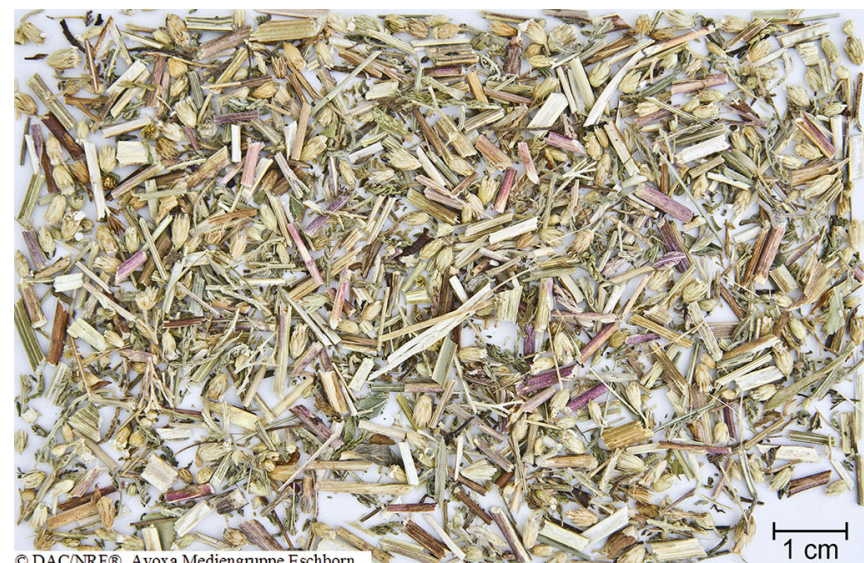
A

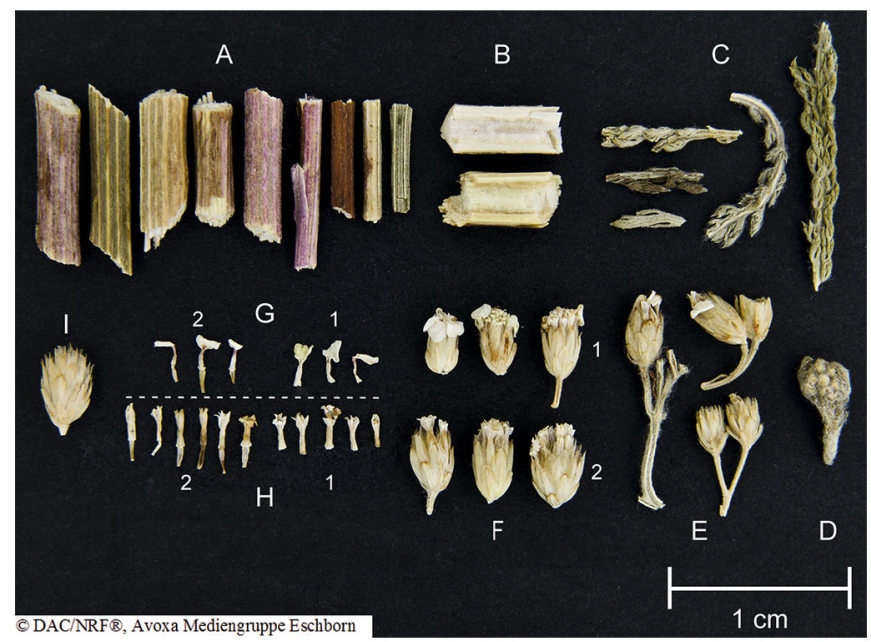

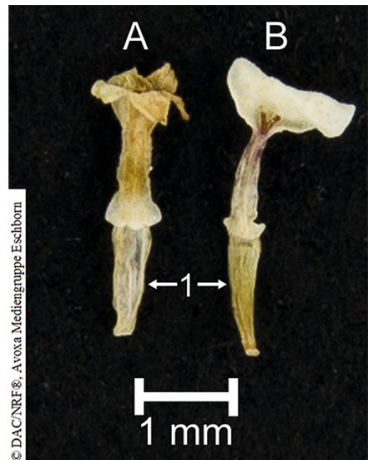

C

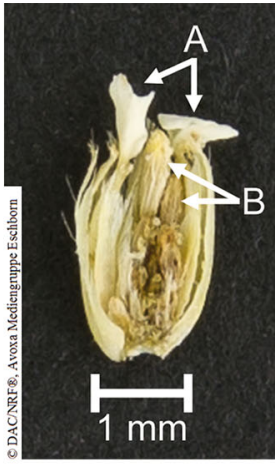

D

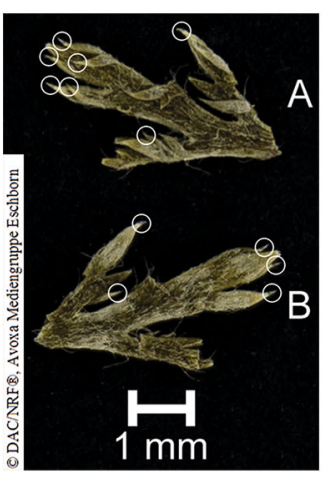

E

B

Fig. 1 a-e Macroscopic characters of Achillea millefolium (all were pictures provided by ${ }^{\odot} \mathrm{DAC} / \mathrm{NRF}^{\circledR}$, Avoxa Mediengruppe Eschborn). a Original seize of the herbal cut material. b Selected fragments of herbal cut material (A) and longitudinal section of the stalks $(\mathbf{B})$, leaf fragments $(\mathbf{C})$, flower head in early stage of blooming (D), blooming flowerheads a spart of the inflorescence (E), single flower heads with (1) and without (2) ray florets (F), ray florets $(\mathbf{G})$ and disc florets $(\mathbf{H})$ without (1) and with (2)

that the key identifying features are discernible and non-conforming features can be detected. This differs with each herb. As can be seen in Figs. 1 and 2, the identifying characteristics of chopped material can be discerned and documented. Macroscopic assessment is not applicable to materials in which the characteristic features are excessively diminished or no longer present, such as powders and extracts. Macroscopy cannot be used to determine the presence of molds (except if visible), metals, pesticides, and other ovary, involucre (I). c Magnification of parts of the herbal cut drug: Longitudinal section of a flower head with outer ray florets (A) and inner disc florets (B). d Magnification of parts of the herbal cut drug: Magnification of a disc (A) and a ray floret (B), with ovary (1). e Magnification of parts of the herbal cut drug: Upper (A) and lower (B) surface view of the pinnatisect leaf fragments, with whitish tips

potential contaminants for which other tests are required. Not all materials can be identified to species, and sometimes, adulterating materials that would not be acceptable as an authentic drug can look similarly to the target botanical.

Microscopic evaluation can help to indicate what the chemist is to look for, and it can assist in supporting the results of chemical assessment. It is a powerfully effective technique for identifying the presence of non-conforming materials such as non- 
target botanicals, complete or partial substitutions and admixtures, filth, insect fragments, visible molds, fillers, and exhausted material. Microscopy is not applicable for the assessment of botanical materials that are so finely powdered that the characteristic structures are no longer recognizable, extracts, and sometimes, closely related species. The combination of organoleptic, macroscopic and microscopic characters provides the highest degree of confidence in physically evaluating raw material. The need for this orthogonal approach to botanical assessment has been addressed by others (Simmler et al. 2015).

As with all analytical techniques, personnel must be adequately trained to perform the above-mentioned assessments in a GMP-compliant manner. Training in classical botanical pharmacognosy in North America and Europe has become rare. There are only few formal training programs teaching these skills, and even academic training in classical botany as a scientific discipline is on a decline in the West. The discipline of pharmacognosy/pharmaceutical biology has tremendously increased and comprises molecular biology, metabolomics, and genetics which have been rightly implemented into the curricula, however, often with lack of sufficient attention allocated to classical botanical pharmacognosy techniques. Throughout Asia and India, where there is a greater adherence to traditional healing principles, such classical training programs still exist.

\section{Chemical assays and spectroscopic methods}

Herb material that is powdered to a degree that uniquely identifying features are no longer present as well as extracts, which lack any cellular elements, require alternative testing. Chemical assays (HPTLC, HPLC) and spectrophotometric methods (UV, IR) provide both qualitative and quantitative information in a single assay. They represent indispensable tools for fingerprinting and quantitation of components in crude and processed herbal material. Using these techniques, it is the "total content" of the sample that can be assessed and is often more in alignment with the concept that the entire plant represents the drug and not one single compound or even multiple compounds. However, many chemical assays can be easily fooled. Goldenseal root for example, one of the bestselling botanical ingredients worldwide due to its antimicrobial properties, is frequently adulterated with other berberine-containing plants with phytochemical similarities to Hydrastis canadensis that are difficult to detect (Liu et al. 2018a, b). Another example are low quality ginkgo extracts which can go undetected in routine screening if spiked with pure flavonoids or extracts from other flavonoid-rich plant sources even when using most pharmacopoeial methods (Avula et al. 2015; Wohlmuth et al. 2014).

\section{Chromatographic methods: HPTLC and HPLC}

By far, the most commonly used chemical techniques in the identification and quality assessment of medicinal plant ingredients are thin layer chromatography/ high performance thin layer chromatography (TLC/ HPTLC) and high performance liquid chromatography (HPLC). Both provide characteristic qualitative and quantitative patterns of constituents. TLC is primarily appropriate for qualitative testing, while HPLC allows for both qualitative and quantitative analysis of individual constituents. TLC is a predominantly manual technique that is quick and inexpensive requiring simple laboratory equipment. While widely used, most prevalently in developing countries, TLC has the disadvantage of poor reproducibility and low sensitivity (Jiang et al. 2010). Many of these disadvantages are partially improved with the development of high performance thin layer chromatography (HPTLC) that introduces a number of automated procedures that allow for greater standardization, and therefore greater reproducibility of chromatographic conditions. TLC has been a consistent identification tool included in most modern pharmacopoeias. In more recent years, greater inclusion of HPTLC, along with chromatographic images, has occurred (Frommenwiler et al. 2018) and more robust and reproducible methods are under development (e.g., HPTLC Association). HPTLC chromatographic fingerprints are used to characterize multiple compounds in a botanical, in most cases can differentiate between closely related species, and can readily detect the presence of adulterants. HPTLC also allows for both qualitative and reliable quantitative results, the latter by converting electronic images into integrable peak profiles by scanning densitometry (Frommenwiler et al. 2018). Another advantage to HPTLC, especially to industry, is that multiple samples (10-20) can be 
screened in a single assay and is among the highest throughput of chemical techniques.

HPLC allows for the qualitative and quantitative determination of defined or undefined single constituents. The detection of individual compounds and detection limits depend on the detection device, which mostly includes ultraviolet-diode array detector (UVDAD), electron light scattering detector (ELSD), or charged aerosol detector (CAD). HPLC and ultraHPLC (UHPLC), an advanced technique with improved separation capacity, offer the possibility for hyphenation with mass spectrophotometry (MS) and nuclear magnetic resonance (NMR) that yields valuable additional structural information (Zhang et al. 2018). Since many spectra are recorded per minute, a huge amount of data is generated within a short time. The large data sets get manageable by combination with chemometrics and allow for profiling and fingerprinting of metabolites. Metabolite profiling comprises the identification and quantification of (selected) metabolites, whereas metabolite fingerprinting is based on comparison of chemical patterns in order to detect matches (Simmler et al. 2016). The latter requires the application of statistical methods for the interpretation of the results (see section below "Statistical methods").

However, TLC/HPTLC and HPLC focus exclusively on phytochemistry and do not include any assessment of the physical properties of the plant. The combination of a physical test (botanical, macroscopic, organoleptic, and/or microscopic) with a chemical test allows for greater confidence in assuring identification and quality. Among the disadvantages of chemical methodologies is that they typically cannot detect the presence of filth and sometimes cannot distinguish between closely related species or nontarget species that have a similar chemical profile.

Spectroscopic techniques: ultra violet (UV), infrared (IR), nuclear magnetic resonance (NMR)

Spectroscopic techniques allow for the quantitation of single (when testing relatively pure substances) or multiple compounds that share similarities in their UV absorbance. Because of this, spectroscopy provides a more holistic view of herbal medicines in contrast to the quantitation of a single compound.

$U V$ spectroscopy for example allows for the comprehensive determination of groups of similarly related compounds, such as proanthocyanidins in many fruits, that are correlated with activity. UV methods are well-established in pharmacopoeias. With few exceptions, these "total contents" represent surrogate markers of the plant and are used in conjunction with physical identification tests. Unlike botanical, macroscopic, and sensory assessment UV methods are not assaying the plant itself, but rather attempts to represent both physical and chemical aspects of the plant. UV quantitation is often time consuming.

$I R$ spectroscopy is a quick method with the advantage of high throughput due to direct measurement of samples without sample preparation. It records the quality and quantity of constituents at the surface of biological materials and encompasses plant specific parameters like a glabrous or hairy epidermis with regard to the chemical composition of the respective epidermal cuticular waxes. Application of IR requires hyphenation with multivariate data analysis ( $\mathrm{Gad}$ et al. 2013). The use of IR spectroscopy derived from successful examination of powdered pure compounds and gained increasing importance within the past decade in the analysis of both herbal extracts as well as crude material. Attenuated total reflection (ATR-IR) and near IR (NIR) are the most commonly applied techniques for the testing of herbal medicinal products. Since ATR-IR has a low penetration depth in the range of $\mu \mathrm{m}$, particle size and homogeneity of the powder strongly influences the result of the measurement. In contrast, NIR takes shorter measurement times and penetrates into the sample up to $\mathrm{cm}$, which makes it less sensitive against inhomogeneous and unpowdered plant material (Pezzei et al. 2018). Even though the assessment of plant material is prone to errors with regard to moisture, degree of comminution, analysis of extracts or crude material etc., the number of applications in plant quality control increases. There are reports on the differentiation between black cohosh species (Tankeu et al. 2018), determination of geographic origin of Chinese Astragalus samples (Zhang and Nie 2010), quality assessment of South African herbal tea blends (Djokam et al. 2017; Sandasi et al. 2018), quantification of constituents (Mavimbela et al. 2018; Pezzei et al. 2018), and most recently even prediction on activities of plant extracts (Nikzad-Langerodi et al. 2017; Pezzei et al. 2018; Schönbichler et al. 2014). However, reliability of IR-based results strongly 
depends on well-developed reference libraries that integrate closely related and potentially adulterating species to ensure that the spectra obtained is accurate to species. For pure compounds large IR-databases do exist. This is not the case for herbal plant material. Such libraries are not yet commercially available and often are not transferable between systems, requiring individual analysts to develop their own reference libraries. They are under development and need to be developed with further data, since the comprehensiveness of the data set determines the predictive power for correct determination of quality, quantity and activity.

Chemical profiling of natural extracts based on $N M R$ is widely used in research with the aim to quickly gain structural information and dereplicate known compounds (Wolfender et al. 2015). Various databases for identification have been compiled and are available such as for flavonoids (Mihaleva et al. 2013). Again the same requirements as for IR apply: There is a need to establish quality of reference libraries to determine the validity of the information. The advantages of NMR are reproducibility, non-destructiveness, and simple sample preparation. Its low resolution and sensitivity as compared to MS, are considered the major limitations in case of low compound levels (Heyman and Meyer 2012). However, NMR in combination with chemometrics is already widely used for assessing adulteration in foodstuffs (Danezis et al. 2016). For routine quality control of herbal drugs and preparations thereof NMR has not yet established itself, even though this is suggested in literature (Kumar 2016). However, the high investment costs of NMR relative to other analytical techniques prevent its widespread use for routine quality control. Hyphenation with NMR presently seems a valuable tool rather for research than for routine quality control in small companies who sell traditional herbal medicines.

\section{Statistical methods}

Every technique and analytical methodology has the ability to generate a result with greater or lesser degrees of accuracy (confidence level). In an ideal world, the level of confidence of each technique or method for each analytical endpoint is determined. Botanical identification has the greatest level of confidence for the identification of living plant material, if the assessor has the requisite skills for making an appropriate identification and if the identification keys are well developed. Whole leaves of Ginkgo biloba can be identified with a $100 \%$ confidence level when identified botanically or macroscopically. However, when powdered or extracted, the level of confidence to identify the material botanically or macroscopically is reduced to zero because the relevant identifying characters are no longer present. Well-developed Ginkgo biloba extracts have a characteristic chemical fingerprint that can be used to both determine identity and quality quantitatively with a high degree of confidence by looking at the suite of compounds, including their ratios, in total.

Conversely, analysis of single marker compounds is often not powerful enough to detect adulterations, such as in the substitution of cranberry fruit extracts with proanthocyanidin-rich extracts from cheaper sources like peanut, which has been reported in Europe and elsewhere (Gafner 2018). These types of adulteration remain undetected if only one or two marker compounds are assessed. In such cases, errorproneness is reduced if the technique or method employed was developed with a high degree of inherent confidence and by comparison of fingerprints to valid reference standard extracts. The entirety of the metabolites (metabolome) present in a plant extract provides a profile characteristic of the ingredient in question, representing a powerful and robust approach to establish the identity of a material based on the chemical composition.

In metabolomic profiling, multiple mixture components are measured simultaneously, typically through the direct assessment of ideally a large collection of spectroscopic or spectrometric (UV, IR, MS, NMR) patterns from numerous samples, or by evaluation of chromatographic fingerprints after separation by HPLC or GC. The assessment of such complex patterns is generally done by multivariate statistical methods (chemometrics). In the unsupervised chemometric evaluation, the entirety (or selected parts) of the spectrum or the chromatogram from all the samples is used to determine how the samples are clustering without any prior decision on a classification. The most frequently used unsupervised statistical procedure is principal component analysis (PCA). PCA reduces the complex, correlated variables of spectra or chromatograms into a series of independent principal components (orthogonal) of systematically decreasing variance. Visual examination of the PCA score plots provides an excellent means of 
determining the similarity or differences of the test materials (Harnly et al. 2012). Principal component analysis has been used, among others, to compare mass spectrometric fingerprints of Panax ginseng, $P$. quinquefolius, and $P$. notoginseng extracts (Chen et al. 2011), or the NOESY spectra of five Actaea species (Harnly et al. 2015), to evaluate the similarity of UPLC-MS chromatograms of green tea (Camellia sinensis) products (Kellogg et al. 2017a, b), to build a model based on FT-IR to distinguish goldenseal (Hydrastis canadensis) from its adulterants (Liu et al. 2018a, b), or to assess commercial saw palmetto (Serenoa repens) products using ${ }^{1} \mathrm{H}$ NMR spectra (Booker et al. 2014). The main plant metabolites responsible for the PCA clustering may be determined using a PCA loadings plot, although these metabolites remain sometimes unidentified. In the green tea example, the loadings plot allowed to identify metabolites (e.g., mycricetin, kaempferol) that were more commonly found in loose green tea and those that were more abundant in green tea extracts (e.g., epicatechin gallate, epigallocatechin gallate, rutin) (Kellogg et al. 2017b).

If the chemometric evaluation is supervised, a set of known samples that are assigned into several classes is used to build a model or models, which are then used to predict the classes of unknown samples. As an example, extracts from roots of goldenseal and coptis (Coptis chinensis and Coptis deltoidea), Oregon grape (Berberis aquifolium), yellow dock (Rumex crispus) and yellow root (Xanthorhiza simplicissima) were evaluated by moving window PCA, soft independent modeling of class analogy (SIMCA), and several models using partial least squares (PLS). While none of the optimized PLS models was able to differentiate among goldenseal and the potential adulterants, SIMCA and moving window PCA were able to detect the adulterant at levels between 2 and 20\% (Liu et al. 2018a, b). SIMCA and PLS-based models have been successfully used in a number of investigations (Beale et al. 2017; Booker et al. 2014; Chen et al. 2011; Harnly et al. 2012; Liu et al. 2018a, b; Shawky and Selim 2018). It is important to emphasize that the supervised statistical models need to be built with a well-defined set of references, most often including both positive controls (known samples) and, in the case of plant material, closely related or potentially adulterating species as negative controls. Attempts to identify the ingredients in commercial products based on a model built with authenticated whole or powdered crude plant material often fail due to admixtures of other herbal ingredients, presence of excipients, or the processing method (various types of extraction and purification steps) can lead to substantial changes in the metabolomics profile. As such, the test sample may not be similar enough to the botanicals or preparations upon which the chemometric model was built (Harnly 2015). Conversely, when extracts are prepared in a manner designed to capture the broad array of compounds that naturally occur within a botanical, versus selectively extracting for a single or more limited number of compounds, there can be a great degree of consistency between the authenticated reference material and a commercial product (Upton et al. 2003).

In almost all cases, the statistical power for determining a particular analytical endpoint is increased when the analytical technique or methodology used is inherently developed to have a high degree of confidence or when multiple analytes or techniques are employed (orthogonal approach).

\section{Botanical and chemical reference materials (BRMs)}

A critical part of many analytical techniques is use of a reference material or standard that can be used as a comparator against which a test sample can be assessed. The National Institute of Standards and Technology (NIST, US) defines reference materials as follows: "Material, sufficiently homogeneous and stable with respect to one or more specified properties, which has been established to be fit for its intended use in a measurement process." Guidelines for the development of reference materials are presented in various guidance documents of the International Organization for Standardization.

A botanical reference material (BRM) is a botanical whose identity has been confirmed by one or more metrics based on the application of scientifically valid techniques and methods in a scientifically valid manner that an analyst can use to ensure that a test sample conforms to what is expected. Most pharmacopoeias and a number of private commercial suppliers produce BRMs. Pharmacopoeial reference materials are often referred to as "compendial" standards. They are designed to meet the monograph 
requirements of the particular ingredient and are used when testing a material for pharmacopoeial conformity, a requirement of drug regulations of most nations. Practically speaking, a BRM may be identified botanically, often with a corresponding archived botanical voucher, macroscopically and organoleptically, chemically, molecularly, or any combination of these techniques. The more disparate (orthogonal) analytical techniques that are applied to the characterization of an individual material, the greater the level of confidence there is in determining the authenticity of the material or standard (Simmler et al. 2015).

A chemical reference standard is similarly a chemical whose identity and purity has been well characterized so that accurate quantitative assessments in analytical chemistry can be made and are referred to as chemical reference materials (CRMs) or chemical reference standards (CRS). Some CRMs/ CRSs, are made to exacting standards explicitly for the purpose of proficiency testing or formal validation of analytical methodologies. Others are made for routine quality control purposes and may not be as well characterized as CRMs used in proficiency testing, but never the less should be appropriately characterized.
For routine quality control purposes of many botanicals it is often not critical to use reference materials unless quantifying a particular compound(s). However, the use of reference materials reflects best practices and is widely encouraged in GMP guidance documents (CFR 2007). For further discussion of reference materials, see (Hauck 2012) and General Chapters of national pharmacopoeias.

\section{Genetic assays}

In recent years, targeted genetic testing has emerged as a set of potential identification techniques for medicinal plants based on approaches widely used to propose taxonomic revisions (Byng et al. 2016; Palhares et al. 2015). The term DNA barcode has been used to describe DNA sequences that can uniquely identify a species. There are three primary organizations dedicated to the advancement of barcoding research: The International Barcode of Life (IBoL 2019), the Consortium for the Barcode of Life (CBoL 2019), and Barcode of Life Data Systems (BoLD 2019). The mitochondrial gene CO1 was proposed as the standard barcode for animal species

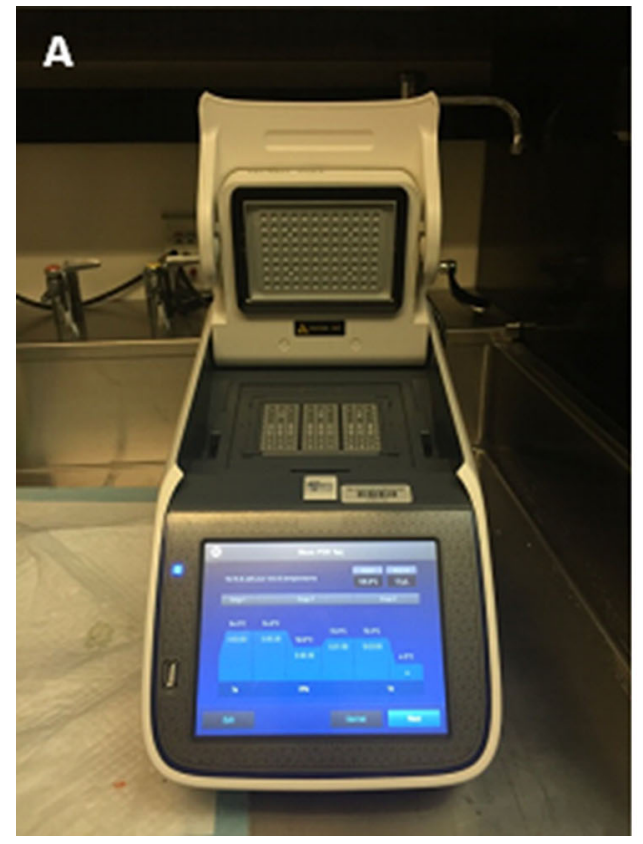

Fig. 2 a Applied Biosystems ${ }^{\mathrm{TM}}$ SimpliAmp ${ }^{\mathrm{TM}}$ PCR Thermal Cycler. b Pacific Biosciences ${ }^{\mathrm{TM}}$ PacBio R5 single molecule sequencing instrument. Image A provided by Natascha Techen,

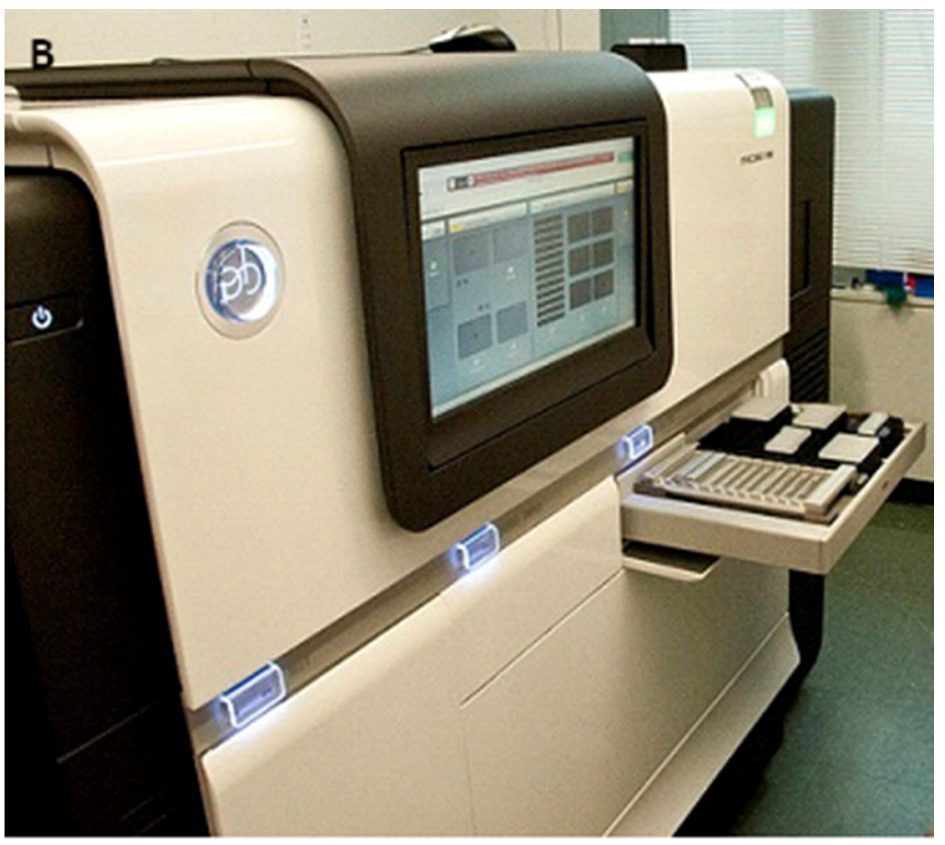

University of Mississippi, National Center for Natural Products Research (Oxford, MS), image B courtesy of the US Food and Drug Administration 
and can be used to distinguish more than $90 \%$ of species in most animal groups (De Boer et al. 2014). Plant genomes, however, evolve more rapidly than those of animals, preventing the establishment of a single universal barcoding locus. In most cases, a combination of two or more genetic loci is required for making a determination of identification with a high degree of confidence (Kress and Erickson 2007). Different organizations recommend the use of groups of different loci for terrestrial plants.

Genetic techniques utilize similarities as well as differences of the genomic information of a plant group to help distinguish among families, genera, species, varieties, or populations. The premise is that a unique set of sequences (a barcode) exists to help identify interspecific (among species) and intraspecific (within one species, e.g. populations from various geographical locations) relationships. This has been highly successful in the identification of animal species. Whereas a relatively short sequence of DNA (648 base-pair region in the mitochondrial cytochrome c oxidase 1 gene [CO1]) can be used for the differentiation of animals, two or more gene regions in plant chloroplasts (e.g. matK and rbcL) are currently used for the identification of plants. The ITS (Internal Transcribed Spacer) 1 and 2 genomic regions are recommended as a core plant DNA barcode. They are very useful in combination with other sequences to reach identification (Cheng et al. 2016). However, because chloroplast genomic regions are only maternally inherited hybrids may not be accurately identified using only chloroplast regions. According to Staats et al. (2016) a suitable barcode for identification at the species level should be able to discern the target species from closely related species with a minimum of a $3 \%$ difference between the species, but the genetic difference may vary amongst taxonomic groups.

Some early techniques used enzymes to digest plant DNA followed by the addition of specific oligonucleotide adapters to the ends of the fragments. A subsequent amplification by polymerase chain reaction (PCR) provides a fingerprint that can be compared to authentic plant material (amplified fragment length polymorphism, AFLP). Other genetic fingerprint techniques amplify plant DNA by PCR using a single primer (a short nucleic acid sequence that serves as a starting point for DNA synthesis) with an arbitrary sequence, resulting in multiple pieces of DNA of different lengths that are separated by gel electrophoresis (e.g., randomly amplified polymorphic DNA [RAPD], or simple sequence repeat [SSR]). The resulting pattern is desired to be species specific. A PCR product of a chosen genomic region can also be subjected to DNA-cutting enzymes. The resulting fragments, separated by gel electrophoresis, can result in a pattern showing differences in the samples analyzed (restriction fragment length polymorphism, RFLP).

More often, however, researchers determine the nucleotide sequence of one or more genetic loci in the plants of interest and identify nucleotide sequences that are characteristic of a given species or sample. Since all living plant cells contain DNA, even very small quantities of plant material allow successful identification of plants, as long as the DNA is intact, and the unique identifying genomic regions and appropriate primers have been determined. Identification of plant material by DNA analysis is relatively simple in a plant like ginkgo, a monotypic species that represents an ancient lineage without any closely related living relatives (Liu et al. 2018a, b). DNA work becomes more challenging but is nevertheless feasible in closely related species.

The general method for determining DNA sequence data from plants includes three main steps: Isolation and purification of the DNA, amplification of targeted sequence regions using the polymerase chain reaction (PCR), and sequencing of the amplified product. The sequencing method has shown to have a substantial impact on the results (Ivanova et al. 2016). Sanger's method of sequencing provides one DNA sequence per sample, and is generally used to answer the questions "What is this (single) species material?" or "Is this species present in the sample?" Newer instruments allow for the detection of sequences of many species from a sample. These more recent advancements in genetic analyses are often referred to as next-generation sequencing (NGS) or DNA metabarcoding. However, there are considerable limitations with NGS regarding its ability to generate scientifically valid test results. Due to its exceptional sensitivity, NGS detects the presence of DNA of minor, often inconsequential, contaminants, such as from pollen or a blade of grass (Raclariu et al. 2018). Some industry analysts attempt to use NGS to provide quantitative data regarding the amount of DNA present in a sample with the premise that the 
majority of the DNA present will represent the majority of the sample. However, the DNA of lesser amounts of a species in a sample may be preferentially amplified over larger amounts of other species. Such findings can result in conclusions that are irrelevant or misleading (Staats et al. 2016).

Once the DNA sequence data have been determined, identity testing can be performed by comparing the test sample sequence data to the sequence data from authenticated reference samples. The data obtained is either consistent with the reference sample or different from the reference sample, indicating the putative identity of the material but absolute species identification cannot be achieved unless the sequence data is available for all other possible plants and microbes.

The key to effective DNA barcode testing is in the compilation of a reliable DNA library from properly identified representatives of wildcrafted or cultivated material that includes closely related species and adulterants. Appropriate experimental set up, e.g. choice of primers, is required to ensure the correct identification. The more samples a library contains, the greater the likelihood is to obtain information regarding interspecific (among species) and intraspecific (within one species, e.g. populations from various geographical locations) relationships. Unfortunately, currently none of the publicly available repositories of genetic sequencing data are validated. As well, the databases are incomplete and many plants are not represented. Repositories of DNA sequences, such as GenBank, are relied upon by many DNA analysts. GenBank is an internationally open access database, produced and maintained by the National Center for Biotechnology Information since 1992 (NCBI 2019). There are smaller databases as The Plant Genome Database Japan's DNA Marker and Linkage Database (PGDBJ 2019). Relying solely on unvalidated publicly available libraries of DNA sequences without critical review can result in erroneous findings. In North America, the scientific validity of genetic testing by commercial laboratories is similarly limited as all commercial DNA services to date utilize proprietary techniques that do not allow for independent and transparent scientific reproducibility or confirmation. Since 2016, international discussions have suggested to expand the scope of the Convention on Biodiversity and the Protocol to include digital sequence information (DSI) as such or its use (CBD
2019). In the meantime, scientists and forums encourage the free sharing of information.

DNA technology has potential for reliable use for confirmation of identification of botanical materials in whole, cut or pre-processed forms, but so far has shown limited success in the assessment of materials that have been ground, dried or otherwise processed (e.g. steam sterilized raw materials, extracts) (Ivanova et al. 2016; Pawar et al. 2017). Genetic techniques are especially useful for authenticating individual components in mixtures of two or more plants, but can only be efficiently analysed, if their mixed DNA can be sequenced in parallel. However, DNA methods work best with samples consisting of crude plant parts of relatively fresh material from a single species. A strength of DNA analysis is its great sensitivity. This allows for detection of DNA from other plant material ranging from incidental traces of pollen to acceptable levels of foreign organic matter (2-8\%), to gross adulterations. Adulterations may be qualitatively detected, but DNA analysis does not provide quantitative results upon which the decision can be made of whether a material is acceptable or not. Minute amounts of DNA of the expected species added to maltodextrin will result in false positive with $100 \%$ of the target species, but nevertheless be adulterated. This strength can also be a weakness in the medicinal plants industry as sprinkling of small amounts of DNA will give a positive result, even if no authentic plant material is present.

While generally limited to providing qualitative data purely for purposes of identification, newer DNA technologies have shown some promise in the area of quantitative analysis. A significant limitation of standard genetic analyses is its inability to discern plant part making it inapplicable for compliance with medicinal plant good manufacturing practices. Because of this, genetic techniques should always be coupled with other techniques (botanical, morphological, microscopic, chemical) for discernment of identity of plant part. Some DNA testing methods are sensitive and easily performed but may be difficult to reproduce (e.g. RAPD), depending on the type of testing used. Furthermore, many herbal preparations consist of more than one species and often contain degraded DNA that might not meet the requirements for accurate and reliable analysis using fragmentbased analytical approaches, such as AFLP, RFLP. 
Sanger sequencing of DNA barcodes may not be the best method of choice for industrial quality control, but application of next-generation sequencing with data of all the potential adulterants of a specific herbal drug represents an interest for quality assurance (Sgamma et al. 2017). It is recommended to use DNA barcoding assays in a manner complementary to other techniques (Palhares et al. 2015).

\section{Isotope fingerprinting}

Multi-isotopic and multi-element methods are officially recognized to trace the provenance of food (Kelly et al. 2005) and are of increasing importance for producers and control agencies (Camin et al. 2016). The basic premise of this technique is that stable ratios of light isotopes (bio-elements: ${ }^{2} \mathrm{H},{ }^{1} \mathrm{H} ;{ }^{13} \mathrm{C},{ }^{12} \mathrm{C} ;{ }^{15} \mathrm{~N}$, $\left.{ }^{14} \mathrm{~N} ;{ }^{18} \mathrm{O},{ }^{17} \mathrm{O},{ }^{16} \mathrm{O} ;{ }^{36} \mathrm{~S},{ }^{34} \mathrm{~S},{ }^{33} \mathrm{~S},{ }^{32} \mathrm{~S}\right)$ and heavy isotopes $\left({ }^{87} \mathrm{Sr},{ }^{86} \mathrm{Sr} ;{ }^{208} \mathrm{~Pb},{ }^{207} \mathrm{~Pb},{ }^{206} \mathrm{~Pb},{ }^{204} \mathrm{~Pb} ;{ }^{144} \mathrm{Nd}\right.$, ${ }^{143} \mathrm{Nd}$ ) are characteristic between species. These ratios represent unique isotopic signatures and are associated to certain geographical regions, since isotopes are incorporated by living organisms like humans, animals, or plants. Stable isotope ratios depend on the composition of water (characterized by $\mathrm{H}$ and $\mathrm{O}$ ), air (characterized by $\mathrm{C}$ and $\mathrm{N}$ ), and soil (characterized by e.g. N, S and Sr), they are influenced by climate, geology, agricultural practises, volcanism, distance from the sea, and anthropogenic effects (Danezis et al. 2016). Analysis of these ratios allows for the assessment of the authenticity of biological material, its origin and its processing (Camin et al. 2016).

Isotope ratio analysis requires precise measurement in order to detect the usually small differences in the isotopic compositions between test samples and the standard (Kelly et al. 2005). Isotope ratio mass spectrometry (IRMS) is used for the determination of light isotope ratios, whereas heavier elements are analysed by thermal ionization mass spectrometry (TIMS) (Coelho et al. 2017). Multicollector inductively coupled plasma mass spectrometry (MD ICPMS) was developed in order to improve ionization efficiency for elements $>7.5 \mathrm{eV}$ ionization energy and to shorten sample preparation and time of analysis (Coelho et al. 2017; Danezis et al. 2016). Recently the Chicago Instrument for Laser Ionization (CHILI) was proposed as new technique for isotope measurement (Coelho et al. 2017; Stephan et al. 2016). For data interpretation various methods of multivariate analysis are employed.

This costly technique has been widely used in the field of food production, and also the number of papers on pharmaceutically relevant herbal drugs has increased. Olive oils from Europe and extra-Europe have been characterized (Bontempo et al. 2019), the geographical origin of imported and domestic Camellia sinensis within Turkey (Cengiz et al. 2017), and the origin of Panax ginseng samples cultivated in Korea (Chung et al. 2018) are reported, and the use of isotopic fingerprint in combination with metabolomics to authenticate Serenoa repens extracts were published recently (Perini et al. 2018). However, preciseness and accuracy of results are critically discussed in literature, as terminology employed by different authors is often not clear. Expression of uncertainty of isotope amount ratios and how it is calculated is often missing, which hinders comparability of results for the establishment of isotope databases. Also the development of matrix matching reference materials would be highly desirable for future isotope ratio measurements (Coelho et al. 2017).

\section{Conclusion}

The need for proper identification of botanical ingredients in medicinal plant products is critical for maximizing their potential for efficacy and minimize the incidence of both economic and potentially toxic adulterations. All analytical techniques are scientifically valid if used in a scientifically valid manner. Classical physical techniques are often mistakenly considered to be less accurate than more mechanized chemical and genetic techniques. Botany remains the primary scientific discipline governing plant identification, while the suite of physical and chemical tests present in pharmacopoeias remain the primary source of test for ensuring the identification, purity, and quality assessment of medicinal plant parts.

All techniques differ considerably in technical equipment/running costs and require a more or less specialized training to provide quality assessment of a botanical with a high degree of confidence. Each technique has strengths and limitations that are applicable or inapplicable depending on the analytical goal. Confidence in the results of all analyses is increased when using a suite of tests (orthogonal 
testing), such as coupling a physical test (botanical, macroscopic, sensory, microscopic) with a chemical (qualitative or quantitative) assay for identity, purity, and quality. Classic botany is not well integrated into the medicinal plant industry. Macroscopic, organoleptic, and microscopic assessment techniques are integral to all pharmacopoeial standards but are often not integrated into industry quality control practices, most especially, in Western countries. Chemical and spectroscopic techniques are most appropriate for quantification of specific compounds but should be coupled with a physical test ensuring identity. Genetic testing is especially valuable for identifying multiple ingredients in a mixture and forensically for identifying potentially adulterating species, but is limited due to lack of transparency of genetic testing used, its inability to discern plant part, and potential to mistakenly amplify non-target species DNA or detect inconsequential levels of foreign matter. Whenever possible, appropriate botanical reference materials should be used as comparators against test samples.

A basic concept in all techniques is whether or not the technique is "fit for purpose". One of the primary tasks of the analyst is to decide which combination of tests is best to apply keeping in mind investment of time, effort, costs, and analytical goal. An increasing awareness of the need to apply an orthogonal approach to medicinal plant evaluation will facilitate quality control at a time when interest in traditional herbal medicines is rapidly growing.

Acknowledgements Open access funding provided by University of Vienna. The authors are thankful to Natascha Techen, University of Mississippi, and Susan Murch, University of British Columbia, for their helpful comments on the "Genetic assays" section.

Open Access This article is distributed under the terms of the Creative Commons Attribution 4.0 International License (http:// creativecommons.org/licenses/by/4.0/), which permits unrestricted use, distribution, and reproduction in any medium, provided you give appropriate credit to the original author(s) and the source, provide a link to the Creative Commons license, and indicate if changes were made.

\section{References}

API (2001) Ayurvedic pharmacopoeia of India, vol 1. Controller Pub Civil Lines, New Delhi
Applequist WL (2006) The identification of medicinal plants: a handbook of the morphology of botanicals in commerce. Missouri Botanical Garden Press, St Louis

Applequist WL (2015) Using traditional taxonomy and vouchers in authentication and quality control. In: Reynertson K, Mahmood K (eds) Botanicals: methods and technologies for quality control. CRC Press, Boca Raton

Avula B, Sagi S, Gafner S et al (2015) Identification of Ginkgo biloba supplements adulteration using high performance thin layer chromatography and ultra high performance liquid chromatography-diode array detector-quadrupole time of flight-mass spectrometry. Anal Bioanal Chem 407:7733-7746

Beale DJ, Morrison PD, Karpe AV, Dunn MS (2017) Chemometric analysis of lavender essential oils using targeted and untargeted GC-MS acquired data for the rapid identification and characterization of oil quality. Molecules 22:E1339

Bennett BC, Balick MJ (2014) Does the name really matter? The importance of botanical nomenclature and plant taxonomy in biomedical research. J Ethnopharmacol 152:387-392

Berg OC, Schmidt CF (1863) Darstellung und Beschreibung sämtlicher in der Pharmacopoea borussica aufgeführten officiniellen Gewächse oder der Teile und Rohstoffe, welche von ihnen in Anwendung kommen, nach natürlichen Familien. Verlag von Arthur R Felix, Leipzig

BoLD (2019) Barcode of life data systems. http://www. barcodinglife.org. Cited 27 Feb 2019

Bontempo L, Paolini M, Fraceschi P et al (2019) Characterisation and attempted differentiation of European and extraEuropean olive oils using stable isotope ratio analysis. Food Chem 276:782-789

Booker A, Suter A, Krnjic A et al (2014) A phytochemical comparison of saw palmetto products using gas chromatography and ${ }^{1} \mathrm{H}$ nuclear magnetic resonance spectroscopy metabolomic profiling. J Pharm Pharmacol 66:811-822

Brickell CD, Alexander C, Cubey JJ (2016) International code of nomenclature for cultivated plants, 9th Ed. International Society for Horticultural Science, Leuven. https://www. ishs.org/sites/default/files/static/sh_18_Sample_chapters. pdf

Byng JW, Chase MW, Christenhusz MJM et al (2016) An update of the angiosperm phylogeny group classification for the orders and families of flowering plants: APG IV. Bot J Linn Soc 181:1-20

Camin F, Bontempo L, Perini M et al (2016) Stable isotope ratio analysis for assessing the authenticity of food of animal origin. Compr Rev Food Sci Food Saf 15:868-877

CBD (2019) Digital sequence information on genetic resources. Convention on biodiversity. https://www.cbd.int/abs/dsigr.shtml. Cited 27 Feb 2019

CBoL (2019) Consortium for the barcode of life. https://www. gbif.org/participant/287. Cited 27 Feb 2019

Cengiz MF, Turan O, Ozdemir D et al (2017) Geographical origin of imported and domestic teas (Camellia sinensis) from Turkey as determined by stable isotope signatures. Int J Food Prop 20:3234-3243

CFR (2007) Code of federal regulations. Current good manufacturing practice in manufacturing, packaging, labeling, 
or holding operations for dietary supplements; Final rule. Food and Drug Administration. Fed Regist 72(21):34752

Chandiraleka E, Hamsalakshmi R (2016) A study on customer awareness and satisfaction of selected ayurvedic \& herbal products. Int J Adv Res Dev 1:6-12

Chen P, Harnly JM, Harrington P de B (2011) Flow injection mass spectroscopic fingerprinting and multivariate analysis for differentiation of three Panax species. J AOAC Int 94:90-99

Cheng T, Xu C, Lei L et al (2016) Barcoding the kingdom Plantae: new PCR primers for ITS regions of plants with improved universality and specificity. Mol Ecol Resour 16:138-149

Chung IM, Kim JK, Lee JH et al (2018) C/N/O/S stable isotopic and chemometric analyses for determining the geographical origin of Panax ginseng cultivated in Korea. J Ginseng Res 42:485-495

Coelho I, Castanheira I, Bordado JM et al (2017) Recent developments and trends in the application of strontium and its isotopes in biological related fields. Trends Anal Chem 90:45-61

Cooper JW, Denston TC, Riley M (1931) A textbook of pharmacognosy. Sir Isaac Pitman \& Sons, Ltd, London

DAC (2016) Deutscher Arzneimittel-Codex. Eds. Bundesvereinigung Deutscher Apothekerverbände e. V. Govi-Verlag, Berlin

Danezis GP, Tsakaris AS, Camin F et al (2016) Food authentication: techniques, trends \& emerging approaches. Trends Anal Chem 85:123-132

Dauncey EA, Irving J, Allkin R et al (2016) Common mistakes when using plant names and how to avoid them. Eur $\mathbf{J}$ Integr Med 8:597-601

De Boer HJ, Ouarghidi A, Martin G et al (2014) DNA barcoding reveals limited accuracy of identifications based on folk taxonomy. PLoS ONE 9:e84291. https://doi.org/10.1371/ journal.pone.0084291

Dijkstra J, Galbraith R, Hodges BD et al (2012) Expert validation of fit-for-purpose guidelines for designing programmes of assessment. BMC Med Educ 12:20-27

Djokam M, Sandasi M, Chen W et al (2017) Hyperspectral imaging as a rapid quality control method for herbal tea blends. Appl Sci. https://doi.org/10.3390/app7030268

Frommenwiler DA, Kim J, Yook C et al (2018) Comprehensive HPTLC fingerprinting for quality control of an herbal drug - the case of Angelica gigas root. Planta Med 84:465-474

Gad HA, El-Ahmady SH, Mohamed IA et al (2013) Application of chemometrics in authentication of herbal medicines: a review. Phytochem Anal 24:1-24

Gafner S (2018) Conference report: workshop on botanical food supplement and herbal medicine adulteration. HerbalEGram 15(12). http://cms.herbalgram.org/heg/ volume15/12December/AdulterationConferenceReport. html?ts $=1545291067 \&$ signature $=c 8 c d c a 4 f 794 a 810 a 899$ ce83953554cfe. Cited 26 Dec 2018

Goodwin ZA, Harris DJ, Filer D et al (2015) Widespread mistaken identity in tropical plant collections. Curr Biol 25:R1066-R1067

Graves J (1834) Hortus medicus, or figures and descriptions of the more important plants used in medicine, or possessed of poisonous qualities. Adam and Charles Black, Edinburgh
Harnly J, Luthria D, Chen P (2012) Detection of adulterated Ginkgo biloba supplements using chromatographic and spectral fingerprints. J AOAC Int 95:1579-1587

Harnly J, Chen R, Sun J et al (2015) MS, NMR, and DNA barcoding, complementary methods for identification and authentication of black cohosh (Actaea racemosa L.). Planta Med 81:1-14

Hauck WW (2012) Primary and secondary reference materials for procedures to test the quality of medicines and foods. USP Council of Experts, USP Reference Standards Committee. Pharm Res 29:922-931

Hexa Research (2017) Herbal medicine market size and forecast, by product (tablets \& capsules, powders, extracts), by indication (digestive disorders, respiratory disorders, blood disorders), and trend analysis. 2014-2024. https://www. hexaresearch.com/research-report/global-herbalmedicine-market. Cited 27 Feb 2019

Heyman HM, Meyer JJM (2012) NMR-based metabolomics as a quality control tool for herbal products. S Afr J Bot 82:21-32

Hooke R (1665) Micrographia or some physiological descriptions of minute bodies made by magnifiying glasses. With observations and inquiries thereupon. Royal Society, London

IBoL (2019) International barcode of life. http://ibol.org. Cited 27 Feb 2019

Ivanova N, Kuzmin ML, Braukmann TWA et al (2016) Authentication of herbal supplements using next-generation sequencing. PLoS ONE 11:e0168628. https://doi.org/ 10.1371/journal.pone.0168628

Jayasundar R, Ghatak S (2016) Spectroscopic and e-tongue evaluation of medicinal plants: a taste of how rasa can be studied. J Ayurveda Integr Med 7:191-197

Jian Y, David B, Tu P et al (2010) Recent analytical approaches in quality control of traditional Chinese medicines-a review. Anal Chim Acta 657:9-18

Kellogg JJ, Wallace ED, Graf TN et al (2017a) Conventional and accelerated-solvent extractions of green tea (Camellia sinensis) for metabolomics-based chemometrics. J Pharm Biomed 145:604-610

Kellogg JJ, Graf TN, Paine MF et al (2017b) Comparison of metabolomics approaches for evaluating the variability of complex botanical preparations: green tea (Camellia sinensis) as a case study. J Nat Prod 80:1457-1466

Kelly S, Heaton K, Hoogewerff J (2005) Tracing the geographical origin of food: the application of multi-element and multi-isotope analysis. Trends Food Sci Technol 16:555-567

Kraemer H (1920) Scientific and applied pharmacognosy. Wiley, New York

Kress WJ, Erickson DL (2007) A two-locus global DNA barcode for land plants: the coding rbcL gene complements the non-coding trnH-psbA spacer region. PLoS ONE 2:e508. https://doi.org/10.1371/journal.pone.0000508

Kumar D (2016) Nuclear magnetic resonance (NMR) spectroscopy for metabolic profiling of medicinal plants and their products. Crit Rev Anal Chem 46:400-412

Leon C, Lin YL (2017) Chinese medicinal plants, herbal drugs and substitutes: an identification guide. Kew Publishing, Kew 
Linnaeus C (1753) Species plantarum. Impensis Laurentii Salvii, Stockholm

Liu Y, Finley J, Betz JM et al (2018a) FT-NIR characterization with chemometric analyses to differentiate goldenseal from common adulterants. Fitoterapia 127:81-88

Liu Y, Wang XY, Wei XM et al (2018b) Rapid authentication of Ginkgo biloba herbal products using the recombinase polymerase amplification assay. Sci Rep 8:8002. https:// doi.org/10.1038/s41598-018-26402-8

Mansfield W (1919) Squibb's atlas of the official drugs. R Squibb, New York

Mansfield W (1926) Mansfield's materia medica and pharmacognosy. William Mansfield, Albany

Mavimbela T, Vermaak I, Chen W et al (2018) Rapid quality control of Sutherlandia frutescens leaf material through the quantification of SU1 using vibrational spectroscopy in conjunction with chemometric data analysis. Phytochem Lett 25:184-190

Meyrick W (1790) The new family herbal or domestic physician. Thomas Pearson, Birmingham

Miao XS, Cui QY, Wu HH et al (2017) New sensor technologies in quality evaluation of Chinese materia medica. Act Pharm Sin B 7:137-145

Mihaleva VV, te Beek TAH, van Zimmeren F et al (2013) MetIDB: a publicly accessible database of predicted and experimental ${ }^{1} \mathrm{H}$ NMR spectra of flavonoids. Anal Chem 85:8700-8707

Morton AG (1981) History of botanical science: an account of the development of botany from ancient times to the present day. Academic Press, London

NCBI (2019) GenBank. National Center for Biotechnology Information. https://www.ncbi.nlm.nih.gov. Cited $27 \mathrm{Feb}$ 2019

Nikzad-Langerodi R, Ortmann S, Pferschy-Wenzig EM et al (2017) Assessment of anti-inflammatory properties of extracts from honeysuckle (Lonicera sp. L., Caprifoliaceae) by ATR-FTIR spectroscopy. Talanta 175:264-272

Oldendick R, Coker A, Wieland D et al (2000) Population-based survey of complementary and alternative medicine usage, patient satisfaction, and physician involvement. South Carolina Complementary Medicine Program Baseline Research Team. South Med J 93:375-381

Palhares RM, Gonçalves Drummond M, Dos Santos Alves Figueiredo Brasil B et al (2015) Medicinal plants recommended by the world health organization: DNA barcode identification associated with chemical analyses guarantees their quality. PLoS ONE 10:e0127866. https://doi.org/ 10.1371/journal.pone.0127866

Parkinson J (1640) Theatrum botanicum: the theater of plants or an herball of a large extent. Tho Cotes, London

Paton A, Allkin R, Belyaeva I et al (2016) Plant name resources: building bridges with users. In: Rakotoarisoa NR, Blackmore S, Riera B (eds) Botanists of the twenty-first century: roles, challenges and opportunities. UNESCO, Paris

Pawar RS, Handy SM, Cheng R et al (2017) Assessment of the authenticity of herbal dietary supplements: comparison of chemical and DNA barcoding methods. Planta Med 83:921-936

Perini M, Paolini M, Camin F et al (2018) Combined use of isotopic fingerprint and metabolomics analysis for the authentication of saw palmetto (Serenoa repens) extracts. Fitoterapia 127:15-19

Pezzei CK, Schönbichler SA, Hussain S et al (2018) Near-infrared and Mid-infrared spectroscopic techniques for a fast and nondestructive quality control of Thymi herba. Planta Med 84:420-427

PGDBJ (2019) The plant genome database Japan's DNA marker and linkage database. http://pgdbj.jp. Cited 27 Feb 2019

Raclariu AC, Tebrencu CE, Ichim MC et al (2018) What's in the box? Authentication of Echinacea herbal products using DNA metabarcoding and HPTLC. Phytomedicine 44:32-38

Reuters (2018) Herbal medicine-2018 Global analysis, growth, trends and opportunities research report forecasting to 2023. April 12. Market research future

Rivera D, Allkin R, Obón C et al (2014) What is in a name? The need for accurate scientific nomenclature for plants. J Ethnopharmacol 152:393-402

Sandasi M, Chen W, Vermaak I et al (2018) Non-destructive quality assessment of herbal tea blends using hyperspectral imaging. Phytochem Lett 24:94-101

Scherf JCF (1792) Dispensatorium lippiacum. Libraria Meyeriana, Lemgoviae

Schönbichler SA, Falser GFJ, Hussain S et al (2014) Comparison of NIR and ATR-IR spectroscopy for the determination of the antioxidant capacity of Primulae flos cum calycibus. Anal Methods 6:6343-6351

Sgamma T, Lockie-Williams C, Kreuzer M et al (2017) DNA barcoding for industrial quality assurance. Planta Med 83:1117-1129

Shawky E, Selim DA (2018) Rapid authentication and quality evaluation of Cinnamomum verum powder using near-infrared spectroscopy and multivariate analysis. Planta Med 84:1380-1387

Simmler C, Chen SN, Anderson J et al (2015) Botanical integrity: the importance of the integration of chemical, biological, and botanical analyses, and the role of DNA barcoding. HerbalGram 106:56-58

Simmler C, Chen S, Anderson J et al (2016) Botanical integrity: part 2 traditional and modern analytical approaches. HerbalGram 109:60-61

Staats M, Arulandhu AJ, Gravendeel B, Holst-Jensen A et al (2016) Advances in DNA metabarcoding for food and wildlife forensic species identification. Anal Bioanal Chem 408:4615-4630

Stephan T, Trappitsch R, Davis AM et al (2016) CHILI-the Chicago instrument for laser ionization-a new tool for isotope measurements in cosmochemistry. Int $\mathrm{J}$ Mass Spectrom 407:1-15

Tankeu S, Vermaak I, Chen W et al (2018) Hyperspectral imaging and support vector machine: a powerful combination to differentiate black cohosh (Actaea racemosa) from other cohosh species. Planta Med 84:407-419

Tournefort JP de (1694) Éléments de botanique, ou méthode pour connoître les plantes. Imprimerie royale, Paris

Turland NJ, Wiersema JH, Barrie FR et al (2018) International code of nomenclature for algae, fungi, and plants (Shenzhen Code). https://www.iapt-taxon.org/nomen/main.php

Upton R et al (eds) (2001) Goldenseal root monograph and therapeutic compendium. American Herbal Pharmacopoeia, Santa Cruz 
Upton R et al (eds) (2003) Ginkgo leaf and Ginkgo dry extract monograph and therapeutic compendium. American Herbal Pharmacopoeia, Santa Cruz

Upton R et al (eds) (2008) Uva ursi leaves monograph and therapeutic compendium. American Herbal Pharmacopoeia, Santa Cruz

Upton R, Graff A, Jolliffe G et al (2011) American herbal pharmacopoeia botanical pharmacognosy-microscopic characterization of botanical medicines. CRC Press, Boca Raton

Wegener T (2017) Patterns and trends in the use of herbal products, herbal medicine and herbal medicinal products. Int J Complement Altern Med 9:00317. https://doi.org/10. 15406/ijcam.2017.09.00317

WHO (1998) Quality control methods for medicinal plant materials. World Health Organization, Geneva. unpaginated

Wichtl M (ed) (2004) Herbal drugs and phytopharmaceuticals, 3rd edn. Medpharm Scientific Publishers, Stuttgart

Wohlmuth H, Savage K, Dowell A et al (2014) Adulteration of Ginkgo biloba products and a simple method to improve its detection. Phytomedicine 21:912-918
Wolfender JL, Marti G, Thomas A et al (2015) Current approaches and challenges for the metabolite profiling of complex natural extracts. J Chromatogr A 1382:136-164

Zhang L, Nie L (2010) Discrimination of geographical origin and adulteration of Radix Astragali using Fourier transform infrared spectroscopy and chemometric methods. Phytochem Anal 21:609-615

Zhang C, Zheng X, Ni H et al (2018) Discovery of quality control markers from traditional Chinese medicines by fingerprint-efficacy modeling: current status and future perspectives. J Pharm Biomed Anal 159:296-304

Zhao ZZ, Chen HB (2014) A concise introduction to Chinese medicinal identification. In: Guo P, Brand E (eds) Paradigm Press. Seattle, WA

Zidorn C (2017) Guidelines for consistent characterisation and documentation of plant source materials for studies in phytochemistry and phytopharmacology. Phytochemistry 139:56-59

Publisher's Note Springer Nature remains neutral with regard to jurisdictional claims in published maps and institutional affiliations. 